\title{
Research on the Technological Development of GSO Small Satellite
}

\author{
Geng Jie ${ }^{1, *}$, Gong Jinggang ${ }^{1}$, Wang Zuowei ${ }^{1}$ and Lyu Nan $^{1}$ \\ ${ }^{1}$ Beijing Institute of Control Engineering
}

\begin{abstract}
The application and technological development of geosynchronous orbit(GSO) small satellite are researched in this paper. Firstly the application field and application value of GSO small satellites are analysed. Secondly, the technology development status of foreign GSO small satellites is overviewed. Then the differences and similarities among GSO small satellite, traditional large satellite and low earth orbit(LEO) small satellite are compared, and characteristic and key technique are systematically studied. Finally, for China's future military and civilian needs, combined with the development trend of modern small satellite technology, the preliminary proposal for the development of China's GSO small satellite are given.
\end{abstract}

\section{Introduction}

Since the U.S. military put forward the concept of modern small satellite in the 1980 s, small satellite has become an important direction of spacecraft development due to its advantages of light weight, good performance, short development cycle and low cost. However, before the MiTEx test, all the launched small satellites were LEO satellites.

Due to the particularity of the geosynchronous orbit (especially geostationary orbit, GEO), the most important satellites of space-based information network are usually located in this orbit. GSO satellites can cover a large area, and they are widely used in civil and military fields, such as communications, navigation, early warning and meteorology. Close monitoring or operations by GSO small satellite is of great significance for in-orbit services, GSO space state mastering, space offensive and defensive ability. Therefore, GSO small satellite has attracted more and more attention. Their application fields mainly include: close monitoring of GSO spacecraft, reconnaissance of GSO spacecraft, inorbit maintenance for large GSO satellites, and countermeasures against GSO spacecraft. In essence, there is no fundamental difference between GSO small satellites and LEO small satellites, but the mission requirements and application occasions of them are different. The different mission requirements lead to differences in design of GSO small satellites and LEO small satellites.

In order to satisfy the mission requirements, the GSO small satellites should have some advantages. For example, the rapid, economical and efficient GSO small satellites research and development process, the large angle attitude maneuvering ability and orbit maneuvering ability, and so on.
In this paper, the technological development of GSO small satellite is researched. Firstly, application of GSO small satellites is analysed and the launched GSO small satellites are overviewed. Then the key technical of GSO small satellites are studied. Finally the conclusion gives preliminary proposal for develop of China GSO small satellites.

\section{Application of GSO small satellites}

\subsection{Civil value of GSO small satellites}

There are a certain number of GEO satellites fail to get into pre-set orbit or malfunction every year in the world. According to the statistics of "UCS database" and other data, on average, 28 satellites and 3 rockets are launched into GEO orbit every year, while only 6 or so satellites successfully leave orbit every year. In addition, there are about 2 GEO satellites fail to get into orbit per year on average, which constitute $7 \%$ of the launched satellites. Among the satellites which get into their pre-set orbit, about $5 \%$ of them malfunction at the beginning of the life, $10 \%$ of them malfunction in the task period, $28 \%$ of them malfunction at the end of life, and about $50 \%$ of them have extended services.

There are mainly long-life (generally 10 to 15 years), high cost (cost is several times more than LEO satellites or even more than 10 times) large satellites in GEO. The damage and failure of GEO satellites will cause great economic loss and social impact. For example, the loss of control of the Defense Support Program (DSP-23) missile pre-guard satellites caused great damage to the United States. Therefore, the GEO satellite service technology should be vigorously developed. The GSO small satellites should be designed and developed to assist satellites to get into orbit, carrying out in-orbit

*Corresponding author: gengjie63@163.com 
maintenance for malfunctioning satellites, extending the life of satellites or assisting them getting out of orbit, etc.. In this way the economic losses can be greatly reduced, and the international reputation can be greatly improved.

GSO small satellite on-orbit services can be applied in several fields $[1,2]$ :

(1) Monitoring in orbit

Visible light, infrared and microwave sensors or electronic surveillance equipment on the GSO small satellites can be used for GEO satellite imaging, attitude and position measurement, or radio signal receiving. In this way the health status of target satellite can be obtained. If there is some fault, the fault type can be located, providing the basis for further processing.

\section{(2) On-orbit servicing}

GSO small satellite can be used to restore the normal function of the GEO satellites. For example, assisting the satellite which fails to get into pre-set orbit to get into the proper orbit, help other satellites to open the panels and antennas, which are failed to be normally open, module replacement to restore the satellite function.

(3) Extending using life of satellites

Such as fuel supply for satellites that has run out of fuel.

\subsection{Military value of GSO small satellites}

Until now all the GSO small satellites those have been sent into orbit are carried out by the US military, which demonstrates the military value of the GSO small satellites. GSO small satellite on-orbit can be applied in the following military fields [3-5]:

(1) Space surveillance.

GSO small satellite has the tracking, approaching, circling and surveillance functions of non-cooperative targets. If many small satellites fly in formation, and each small satellite is equipped with different types of detectors, a network observer can be formed. The network observer can simultaneously observes and surveil an area or a target, and the all directions surveillance and high precision can be achieved.

(2) Space-based information countermeasures

Small satellites equipped with microwave jammers can carry out effective space information countermeasures system. By following or circling, the most advantageous position and time can be selected to intercept enemy space information link data and measurement/control signals, and spoofing and jamming can be carried out to weaken the support ability of enemy military information network for the combat system. Because the microwave jammer is mounted on the GSO small satellite, which is close to the target, there is not much power needed for microwave transmission. At the same time, multiple small satellite formations can be set to circle and fly to continuously interfere with multiple azimuth of the target.

(3) Proximity operation or destruction

GSO small satellite has the ability to get close and capture satellite, Also they are difficult to be detected by ground-based visible light observation equipment or radar. The stealth capability makes them be easy to close to other satellites even more carry out hostile actions, such as refusing to ground communication, emptying storage of propellant, or implement permanent damage, etc.

\section{Overview of foreign GSO small satellites}

All the GSO small satellites which have been launched are United States' technical test satellites with military applications, including MiTEx satellites launched in 2006 and GSSAP \& ANGELS launched in 2014 and 2016.

\subsection{MiTEx [6-7]}

The Micro-satellite Technology Experiment (MiTEx) program is a classified project led by the Defense Advanced Research Projects Agency (DARPA). MiTEx consists of two inspection satellites and an experimental upper stage. Two $225 \mathrm{~kg}$ satellites-one produced by Lockheed Martin and one by Orbital Sciences Corp(OSC)-were delivered to GSO by an upper stage built by the Naval Research Laboratory (NRL).

The two MiTEx satellites(MiTEx-A and MiTEx-B) are launched by a Boeing Delta II booster on 21 June 2006.

Budget documents state that the DARPA/US Air Force Microsatellite Demonstration Science and Technology Experiment Program (MiDSTEP), of which MiTEx is a part, is aimed at developing technology for high-performance microsatellites "across the continuum from low Earth orbit (LEO) to deep space GSO environment."

Technologies listed for development under MiDSTEP included optical space surveillance, situational awareness sensors, lightweight power systems, chemical and electric propulsion systems, advanced lightweight structures, miniature navigation technologies, autonomous operations, and high thrust solar thermal propulsion for responsive orbit transfer.

In January 2009 it was reported that the satellites had been specially manoeuvred around the geosynchronous arc to rendezvous with and inspect the disabled DSP-23 satellite, which was drifting eastward. One MiTEx, parked west of DSP-23 over the mid-Atlantic, was commanded to begin moving east during the second week of December 2008. Ground-based amateur observations indicated that a prolonged rendezvous began about 23 December. The other MiTEx, located to the east of DSP 23, was manoeuvred west along the geosynchronous arc and flew past the DSP on 1 January 2009. Reports by amateur observers indicate that both satellites are now in retirement orbits and no longer in active service.

MiTEx satellites indicating that the technology of GSO small satellite in the United States has entered the mature and engineering application stage. 


\subsection{GSSAP \& ANGELS [8-10]}

The GSSAP (United States launched two Geosynchronous Space Situation Awareness Program) satellites into orbit by a United Launch Alliance Delta IV $\mathrm{M}+(4,2)$ booster from SLC-37, Cape Canaveral Air Force Station (AFS), Florida, on 25 July 2014. The AFSPC-4 mission also carried one secondary payload, known as ANGELS (Automated Navigation and Guidance Experiment for Local Space). The success of the mission marks the maturity of the U.S. GSO space surveillance technology, and the rapid improvement of the detection, tracking and reconnaissance capabilities of GSO targets, which has attracted high attention from the space industry.

As shown in the following Fig., a Delta IV Medium+ rocket carried twin USAF GSSAP satellites and the ANGELS satellite on the AFSPC-4 mission.

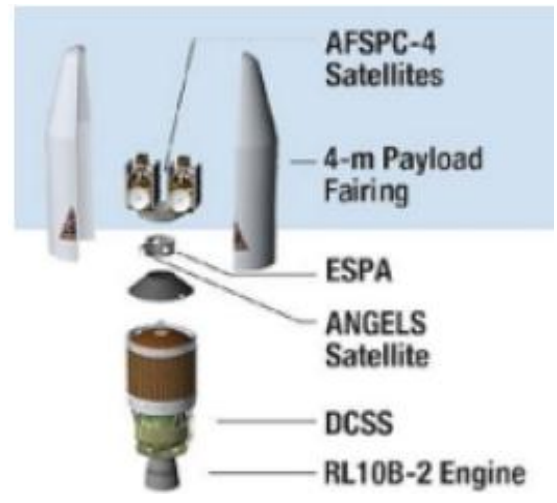

Fig. 1. GSSAP \& ANGEL sketch map of launching mission

\section{(1) GSSAP satellites}

GSSAP is a two-satellite system that operates a near geosynchronous orbit regime to provide accurate tracking and characterization of man-made orbiting objects. Built by Orbital ATK of Dulles Virginia, the GSSAP satellites are controlled by operators at Schriever Air Force Base in Colorado Springs, Colorado.

Each GSSAP satellite had a launch mass of approximately 650 to $700 \mathrm{~kg}$. They must carry a considerable amount of propellant, probably using a hydrazine monopropellant propulsion system, to make frequent orbit adjustments and perform station-keeping manoeuvres. Small thruster burns enable them to observe chosen targets by setting up favourable passes.

GSSAP satellites have GEO patrol detection and close up detailed investigation ability. In daily operation, they drift in the geostationary belt to scan the orbit, accurately detect the target, and make multi-angle threedimensional observation of specific target. If necessary, it can also close to GEO target for detailed reconnaissance and obtain high-definition view of target through orbital maneuver. It can be seen that the space situational awareness capability of GSSAP satellite has gone beyond the basic application level and develop to timely and detailed perception. Also they have the ability to support the intelligence acquisition, technical capability analysis, operation intention judgment, threat assessment and response of space operations.
Two more GSSAP satellites, also built by Orbital Sciences, were launched from Space Launch Complex37B at Cape Canaveral AFS on 19 August 2016 on board a ULA Delta IV M+(4,2) rocket. The mission was dubbed Air Force Space Command mission No.6 (AFSPC-6). Like their predecessors, GSSAP-3 and -4 will drift in the geostationary belt. These next two satellites will add to that capability and enable US to understand more completely things that occur in the geosynchronous orbit to a very high quality. It's a key piece in the puzzle for space situational awareness.

\section{(2) ANGELS}

ANGELS was launched as a secondary payload on the AFSPC-4 (GSSAP) mission. It was located beneath two GSSAP satellites.

The experimental ANGELS satellite programme is managed by the Air Force Research Laboratory(AFRL) Space Vehicles Directorate, headquartered at Kirtland Air Force Base (AFB), New Mexico. As part of AFRL's research into advanced Space Situational Awareness (SSA), ANGELS is designed to test techniques for providing detailed information about objects in Earth orbit in an effort to protect US military space assets.

During its planned one-year mission, ANGELS is intended to test several new spacecraft technologies and operations methodologies. The spacecraft hosts an SSA sensor payload to evaluate techniques for detection, tracking, and characterisation of space objects, as well as attribution of actions in space. ANGELS will evaluate these SSA techniques in a limited region around the second stage of the Delta IV rocket, testing manoeuvring concepts above geosynchronous Earth orbit (GEO), where most comsats reside.

Additional payloads that aid spacecraft operations include a GPS system for GEO and high performance accelerometers. This system uses advanced algorithms from NASA to receive GPS side lobe signals and generate near-continuous navigation solutions. The highperformance accelerometers precisely measure small spacecraft accelerations for enhanced guidance and navigation while the experimental onboard vehicle safety system explores methods for dramatically reducing the probability of collision with other space objects in an increasingly congested space environment.

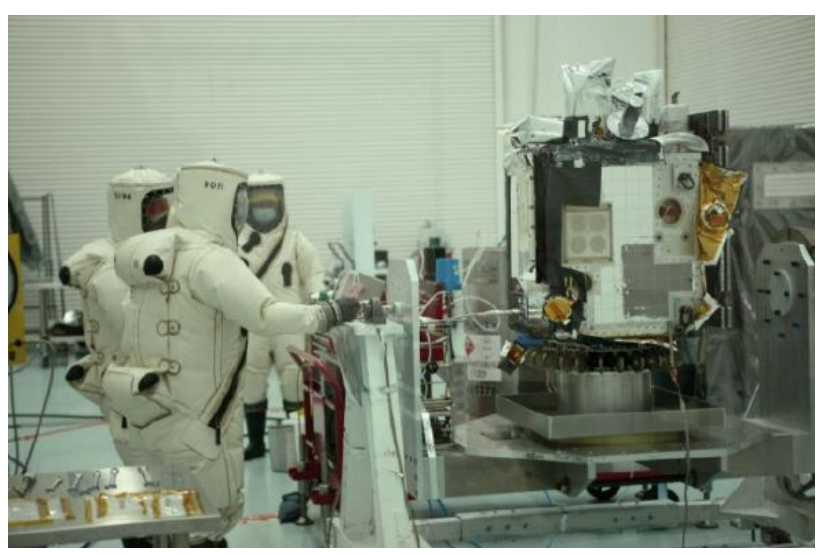

Fig. 2. The ANGELS spacecraft during ground processing prior to launch (USAF) 


\section{Key technology of GSO small satellite}

\subsection{Characteristics and key techniques of GSO small satellite}

Based on the above analysis, the GSO small satellite are of great value in civilian and military. Mainly applications include: 1) GSO target reconnaissance and surveillance, including pictures, listen, close up reconnaissance, etc. 2) In-orbit GEO services, including fuel refueling, in-orbit maintenance and module replacement, auxiliary into-orbit or off-orbit service. 3) Attack and defense of GSO space, such as interference, destruction, etc. 4) GEO networking applications, including composition of communication constellation, etc.

To satisfy above requirements, GSO small satellites should have the following characteristics.

(1) Lightweight and miniaturization design.

(2) Modularization and standardized design.

(3) The ability of large angle, high precision and rapid attitude maneuver.

(4) The ability of wide range, high precision and rapid orbit maneuver.

(5) The ability of autonomous work for long periods of time.

Following table shows similarities and differences between GSO small satellite, traditional large satellites and LEO small satellites.

Table 1. Similarities and differences between GSO small satellite, traditional large satellites and LEO small satellites

\begin{tabular}{|c|c|c|c|}
\hline No & $\begin{array}{c}\text { GSO small } \\
\text { satellite }\end{array}$ & $\begin{array}{c}\text { Traditional } \\
\text { large satellites }\end{array}$ & $\begin{array}{c}\text { LEO small } \\
\text { satellites }\end{array}$ \\
\hline 1 & $\begin{array}{l}\text { Small volume, } \\
\text { light weight, low } \\
\text { power } \\
\text { consumption }\end{array}$ & $\begin{array}{l}\text { Big volume, } \\
\text { heavy weight, } \\
\text { high power } \\
\text { consumption }\end{array}$ & $\begin{array}{l}\text { Small volume, } \\
\text { light weight, } \\
\text { low power } \\
\text { consumption }\end{array}$ \\
\hline 2 & $\begin{array}{l}\text { Short satellite } \\
\text { development } \\
\text { cycle, low cost }\end{array}$ & $\begin{array}{l}\text { Long satellite } \\
\text { development } \\
\text { cycle, high cost }\end{array}$ & $\begin{array}{c}\text { Short satellite } \\
\text { development } \\
\text { cycle, low cost }\end{array}$ \\
\hline 3 & $\begin{array}{l}\text { Modularized } \\
\text { function, } \\
\text { standardized } \\
\text { interface }\end{array}$ & $\begin{array}{c}\text { Weak } \\
\text { modularization } \\
\text { and } \\
\text { standardization }\end{array}$ & $\begin{array}{l}\text { Modularized } \\
\text { function, } \\
\text { standardized } \\
\text { interface }\end{array}$ \\
\hline 4 & $\begin{array}{c}\text { High degree of } \\
\text { autonomous and } \\
\text { intelligent }\end{array}$ & $\begin{array}{l}\text { Lower level of } \\
\text { autonomous } \\
\text { and intelligent }\end{array}$ & $\begin{array}{l}\text { High degree of } \\
\text { autonomous } \\
\text { and intelligent }\end{array}$ \\
\hline 5 & $\begin{array}{c}\text { Mainly } \\
\text { applications are } \\
\text { patrol, defense, } \\
\text { and on-orbit } \\
\text { service for GEO } \\
\text { target. }\end{array}$ & $\begin{array}{c}\text { Mainly } \\
\text { applications are } \\
\text { communication } \\
\text { s, remote } \\
\text { sensing, and } \\
\text { navigation for } \\
\text { ground target. }\end{array}$ & $\begin{array}{c}\text { Mainly } \\
\text { applications are } \\
\text { remote sensing, } \\
\text { reconnaissance, } \\
\text { science } \\
\text { experiments for } \\
\text { ground target. }\end{array}$ \\
\hline 6 & $\begin{array}{l}\text { Fast attitude } \\
\text { maneuver }\end{array}$ & $\begin{array}{l}\text { No need for } \\
\text { fast attitude } \\
\text { maneuver }\end{array}$ & $\begin{array}{l}\text { Fast attitude } \\
\text { maneuver }\end{array}$ \\
\hline 7 & $\begin{array}{c}\text { Fast orbit } \\
\text { maneuver(fly } \\
\text { around target } \\
\text { satellite) }\end{array}$ & $\begin{array}{l}\text { Orbit station } \\
\text { keeping }\end{array}$ & $\begin{array}{c}\text { Orbital } \\
\text { maintenance or } \\
\text { orbit height } \\
\text { maneuver with }\end{array}$ \\
\hline
\end{tabular}

\begin{tabular}{|c|c|c|c|}
\hline 8 & $\begin{array}{c}\text { Launching cost is } \\
\text { high }\end{array}$ & $\begin{array}{c}\text { Launching cost } \\
\text { is high }\end{array}$ & $\begin{array}{c}\text { Launching cost } \\
\text { is low }\end{array}$ \\
\hline 9 & $\begin{array}{c}\text { Long life, high } \\
\text { reliability }\end{array}$ & $\begin{array}{c}\text { Long life, high } \\
\text { reliability }\end{array}$ & $\begin{array}{c}\text { Short life-span, } \\
\text { lower reliability }\end{array}$ \\
\hline 10 & $\begin{array}{c}\text { Harsh space } \\
\text { environment }\end{array}$ & $\begin{array}{c}\text { Harsh space } \\
\text { environment }\end{array}$ & $\begin{array}{c}\text { Relatively } \\
\text { better space } \\
\text { environment }\end{array}$ \\
\hline
\end{tabular}

(1) Compared with the traditional large satellite, the function and structure of the GSO small satellite are relatively simple. It has lower cost, shorter development cycle and higher effectiveness-cost ratio. In particular, functional backup can be achieved through networking by of some number of small satellites. With the same cost and time constraint, it is possible to obtain better performance than a single large satellite.

(2) Compared with LEO small satellites, the launch cost of GSO small satellite is higher and the space environment is more severe. Therefore the cost of GSO small satellite is higher than that of the same type of LEO satellite. In order to make up for the inadequacy of costs, its working life needs to be extended to raise its effectiveness-cost ratio.

In a word, the outstanding contradiction between low cost and high performance of GSO satellite is more prominent than that of large satellites in GSO and small satellites in LEO. Therefore, in the development of GSO small satellite, we must focus on this constraint.

\subsection{Key Technology of GSO small satellite}

Based on the analysis of foreign GSO small satellites, following key technologies in the research and development of GSO small satellite are summarized:

(1) GSO satellite miniaturization, high integration and rapid development technology

The miniaturization and high integration technology includes satellite lightweight power supply, propulsion, integrated electronics and structure design technology, components selection based on the COTS, etc. For the whole satellite project, low-cost rapid development and rapid launch technology supported by new technologies should also be included.

(2) Long-term autonomous running technology

In order to obtain overall GSO space situation, GSO small satellite needs to close up other satellites and run in the area outside visible range of their ground control stations for a long time. Therefore autonomous technology needs to be developed, including GSO longterm autonomous navigation technology, long-term autonomous task management technology (including autonomous task planning and scheduling, load coordination management, on-board data processing, fault diagnosis and recovery technology, etc.).

(3) Guidance and control technology in the process of autonomous rendezvous, close and dock

This technology includes active orbit control technology for circling the space target, the guidance and control technology for tracking, getting close or docking at the target which is maneuvering or out of control.

(4) Efficient fast-response propulsion technology 
In the process of close up operation mission, satellite requires multiple maneuvering, which puts forward high demands on propulsion system. Because of more operation task and long working period, satellite needs to carry more propellant to provide continuing orbit maneuver ability.

(5) Fast attitude maneuver and tracking technology

In order to realize the non-cooperative target monitoring and tracking, the satellite attitude has to be adjusted in real-time according to the target satellite. Fast attitude maneuver and tracking ability are required. In order to achieve "in-motion imaging" and "continuous tracking", the control system is required to provide sufficient control bandwidth and attitude stability.

(6) Imaging recognition of space target and relative position measurement technology

With the visible light, laser radar image information of the target satellite, 3D model of the target satellite can be obtained. The physical shape information can be used for catch operation. Non-cooperative space target attitude and position measurement technology, in orbit three-dimensional model reconstruction technology of space target, feature extraction and tracking measurement technology of space target should be developed.

\subsection{Electronic information architecture of GSO small satellite}

In order to realize the requirements and key technologies of GSO small satellite, the design of electronic information architecture is important. The subsystems of traditional satellite are developed independently, then the whole satellite assembly is integrated. There are many kinds of data buses among subsystems and each machine with in the subsystem. The bus interfaces and the topology are different. For better universality and extensibility of the small satellite architecture, the electronic information architecture of small satellite should use the unified bus network to realize the interconnection of each function module. The bus must satisfy the following characteristics.

(1) High speed. It can realize fast transmission of large amounts of data.

(2) Real-time. On one side the data should arrive at the specified time, and on the other side the jitter of event transmission is relatively fixed,

(3) High reliability. It should have good fault-tolerance and redundant data channels.

(4) Good scalability. Multi-terminal access can be realized.

(5) Simple interface. There is less signal, and easy to plug.

The core of information architecture design is to select the appropriate bus architecture. Time trigger Ethernet(TTE) is a kind of data bus which can satisfy the above characteristics. Therefore a satellite system structure scheme can be designed based on TTE bus, and the unified network is used for spaceborne electronic products interconnection. In this way the system fault tolerant ability can be improved. Long life, high reliability and efficient data operation service are provided. Standardized interface can simplify the design of hardware and cable design, which can realize effective weight loss and facilitate the implementation of the module change operation in orbit.

\section{Conclusion}

Because of its civil and military value, GSO small satellite has gradually become a trend of future satellite development. Considering future military and civilian requirement of our country, combined with the technology development trend of modern small satellite, some preliminary suggestions for GSO small satellite development are proposed.

(1) Situational awareness and GSO space service should be taken as typical application background, based on which the GSO small satellite platform should be researched and developed.

(2) Develop a new generation of electronic information architecture. The overall scheme of distributed, modular and extensible electronic information architecture system should be proposed, and the related interface standards should be gradually unified.

(3) Develop the lightweight, miniaturization, modularization, standardized component technology. This is the basic requirement to reduce the cost of GSO small satellites and improve their effectiveness-cost ratio.

(4) In terms of attitude and orbit control, three key techniques should be focused: large angle attitude maneuver technology, high precision, fast, and wide range orbit maneuvering technology, long-term independent health management and independent survival technology.

(5) Propose rapid development process and management technology suitable for our country with foreign advanced management mode of small satellite development taken into consideration.

\section{References}

1. Galabova K K, Weck O L. Acta Astronautica, 58, 485 (2006).

2. Kaiser C, Sjoberg F, Delcura J M, et a1. Acta Astronautica, 63, 400 (2008).

3. Aaron Q Rogers. 30th Space Symposium, 2014.05.21

4. FU K,FANG X H, PANG X L, et a1. Equipment Manufactring Technology, 3, 79(2010).

5. Michael Osborn, Craig Clauss, Barney Gorin, et al. 43rd AIAA/ASME/SAE/ASEE Joint Propulsion Conference \& Exhibit, AIAA-2007-5434

6. IHS Jane's. Space Systems and Industry, Spacecraft - Technology Demonstration, United States, 22-Jul2015 
7. Arnold Barmettler. Satellite found for 'MiTEx'[E13/OL]. [2013-11-09] http://www.calsky.com/cs.cgi.html

8. IHS Jane's. Space Systems and Industry, Spacecraft - Defence, United States, 13-Sep-2016
9. New U.S. Air Force. Space News, 2015-01-12

10. IHS Jane's. Space Systems and Industry, Spacecraft - Defence, United States, 22-Jun-2015 